\title{
BMJ Open Impact of comorbidity on risk of venous thromboembolism in patients with breast cancer: a Danish population-based cohort study
}

\author{
Anne Gulbech Ording, ${ }^{1}$ Erzsébet Horváth-Puhó, ${ }^{1}$ Jens Peter Garne ${ }^{2}$ \\ Petra Witt Nyström, ${ }^{3}$ Mogens Vyberg, ${ }^{4}$ Henrik Toft Sørensen, ${ }^{1}$ Timothy L Lash ${ }^{1,5}$
}

To cite: Ording AG, HorváthPuhó E, Garne JP, et al. Impact of comorbidity on risk of venous thromboembolism in patients with breast cancer: a Danish populationbased cohort study. BMJ Open 2014;4:e005082. doi:10.1136/bmjopen-2014005082

- Prepublication history and additional material is available. To view please visit the journal (http://dx.doi.org/ 10.1136/bmjopen-2014005082).

Received 18 February 2014

Revised 11 May 2014

Accepted 16 May 2014
CrossMark

For numbered affiliations see end of article.

Correspondence to Dr Anne G Ording; ao@dce.au.dk

\section{ABSTRACT}

Objectives: To assess the interaction between comorbidity and breast cancer (BC) on the rate of venous thromboembolism (VTE) beyond what can be explained by the independent effects of $B C$ and comorbidity.

Design: Population-based matched cohort study. Setting: Denmark.

Participants: Danish patients with $B C(n=62376)$ diagnosed in 1995-2010 and a comparison cohort of women without $B C(n=304803)$ from the general population were matched to the patients with $\mathrm{BC}$ on year of birth in 5-year intervals and on the specific diseases included in the Charlson Comorbidity Index $(\mathrm{CCl})$ and atrial fibrillation and obesity.

Measures: The rate ratios of VTE per 1000 personyears (PY) were computed by comorbidity levels using the $\mathrm{CCl}$, and interaction contrasts (IC) were calculated as a measure of the excess or deficit VTE rate not explained by the independent effects of $B C$ and comorbidity.

Results: Among patients with $\mathrm{BC}$ with a $\mathrm{CCl}$ score of 1 , the $0-1$ year VTE rate was $12 / 1000$ PY, and interaction accounted for $10 \%$ of the rate $(\mathrm{IC}=3.2,95 \%$ $\mathrm{Cl} 0.5$ to 5.9). Among patients with $\mathrm{BC}$ with $\mathrm{CCl} \geq 4$, the VTE rate was 17, and interaction accounted for $8 \%$ of the rate $(\mathrm{IC}=1.2,95 \% \mathrm{Cl}-1.8$ to 4.2$)$. There was no interaction during 2-5 years of follow-up.

Conclusions: There was only little interaction between $\mathrm{BC}$ and the $\mathrm{CCl}$ score on the rate of VTE.

\section{BACKGROUND}

Venous thromboembolism (VTE), that is, deep venous thrombosis (DVT) and pulmonary embolism (PE), is associated with high morbidity and mortality, in particular during hospitalisation. ${ }^{1}$ Cancer and VTE are strongly related and VTE can be a marker of occult cancer as well as a serious complication of cancer. ${ }^{2}$ Cancer-associated VTE risk is up to seven times higher compared to that of the general population, ${ }^{3-5}$ and the rate is mainly

\section{Strengths and limitations of this study}

- The study included all Danish patients with breast cancer diagnosed in 1995-2010 and a comparison cohort of women from the general population free of breast cancer. The study had complete follow-up on all participants from the nationwide Danish Civil Registration System.

- The study was conducted in a government financed healthcare system with equal access for the entire Danish population.

- The validity of the Danish National Registry of Patients as a source of information on comorbidity and venous thromboembolism has varying completeness and validity for different diseases.

- The Charlson Comorbidity Index as a measure of the combined burden of comorbidity does not allow for estimation of disease severity and duration.

increased during the first year following cancer diagnosis. ${ }^{3} 6$ Important risk factors include cancer type and cancer stage, but may also be related to treatment including chemotherapy and central venous catheters used for treatment administration. ${ }^{178}$

Breast cancer $(\mathrm{BC})$ is the most common cancer among women in most of the developed world, ${ }^{9}$ and an estimated $20 \%$ of patients are burdened with major comorbid conditions at diagnosis. ${ }^{10}$ While there is evidence for a link between some diseases, such as stroke, heart failure and osteoporosis, and risk of VTE ${ }^{11-14}$ it is largely unknown how chronic diseases in $\mathrm{BC}$ affect the risk of VTE compared to the general population free of BC.

To the best of our knowledge, no studies have compared the risk of VTE among patients with $\mathrm{BC}$ to a comparison cohort of women free of BC from the general population and accounted for comorbidity. We computed the interaction contrast (IC) as a measure of interaction between $\mathrm{BC}$ and 
comorbidity levels using the Charlson Comorbidity Index (CCI) as a measure of comorbidity. ${ }^{15}$ The IC is an estimate of the VTE rate that cannot be explained by the effects of BC or comorbidity acting alone. ${ }^{16}$

\section{METHODS}

\section{Design and setting}

To compare VTE rates in a cohort of patients with BC with corresponding rates in a cohort of women free of $\mathrm{BC}$, we designed a nationwide cohort study including all patients diagnosed with BC in Denmark between 1995 and 2010 and a comparison cohort of women were selected from the general population. Women in the comparison cohort were matched to each patient with $\mathrm{BC}$ on year of birth in 5-year intervals and on the specific diseases included in the CCI, and on history of atrial fibrillation and obesity, as atrial fibrillation is treated with anticoagulation and obesity is a risk factor for VTE. ${ }^{15} 1718$

The study used administrative and medical registries in Denmark, where the national healthcare system provides tax-supported access to primary care and hospitals for all legal residents. ${ }^{19}$ The Civil Registration System (CRS) maintains up-to-date information on vital and civil status for all Danish residents. ${ }^{20}$ Since 1968, all residents of Denmark have been assigned a Civil Personal Registration (CPR) number, which facilitates accurate linkage between medical registries. This study made use of such registries to provide information on $\mathrm{BC}$ and other hospital diagnoses (see online supplementary appendix).

\section{Ascertainment of the $\mathrm{BC}$ and comparison cohorts}

The Danish Cancer Registry (DCR) was established in 1943 and records all cancers diagnosed in Denmark. $^{21}{ }^{22}$ We identified all female patients with BC diagnosed between 1995 and 2010 and excluded patients with a VTE diagnosis preceding the index (diagnosis) date. For women in the comparison cohort, the index date was defined as the date of BC diagnosis for the matched case.

From the CRS, we selected up to five women from the general population and matched them without replacement to each patient with $\mathrm{BC}$ on age (5-year intervals) and on hospital history of specific comorbidities included in the CCI ${ }^{15}$ and in the presence/absence of atrial fibrillation and obesity. We were unable to find matched comparison women to 428 patients with BC due to high age and many comorbidities, which precluded matching. Women in the comparison cohort could not have previous diagnostic codes for BC or VTE as of the date of $\mathrm{BC}$ diagnosis for the corresponding case but were eligible for inclusion in the $\mathrm{BC}$ cohort if they developed BC.

\section{Comorbidity}

The Danish National Registry of Patients (DNRP) contains information on all non-psychiatric discharge diagnoses for inpatient hospitalisations since 1977. Information on visits to outpatient specialist and emergency departments was added from 1995. The DNRP records diagnoses and dates of hospital contacts. ${ }^{23}$ This registry was used to identify all diagnoses of diseases included in the CCI, ${ }^{15}$ as well as atrial fibrillation and obesity for members of the two cohorts (see online supplementary appendix). Atrial fibrillation and obesity were included in the CCI with a weight of one.

\section{Venous thromboembolism}

The study outcome was VTE, defined as any inpatient or outpatient discharge diagnosis of PE, DVT or other VTE diagnosed after the index date (see online supplementary appendix), thereby excluding VTE that was only diagnosed at emergency departments due to a low positive predictive value. ${ }^{24}$ Owing to the little impact on mortality risk associated with DVT alone, patients coded as having both DVT and PE on their first diagnosis date were classified as patients with PE.

\section{Follow-up}

The $\mathrm{BC}$ and comparison cohorts were followed from the index date until the first occurrence of VTE, death, emigration or 5 years of follow-up, whichever came first. If a matched comparison cohort member received a $\mathrm{BC}$ diagnosis, follow-up was censored and the woman was switched to the BC cohort. The person-time was divided into two survivor cohorts, the first with 1 year of follow-up and the second with $2-5$ years of follow-up.

\section{Statistical analysis}

First, we computed proportions of women in the BC cohort and the matched comparison cohort within categories of age $(0-59,60-69,70-79$ and $\geq 80$ years $)$, index year (1995-1999, 2000-2004 and 2005-2010), baseline CCI score $(0,1,2-3, \geq 4)$, individual CCI comorbidities, presence/absence of atrial fibrillation and obesity, and-for the BC cohort-BC stage at diagnosis (local, regional, distant or unknown).

Next, we computed cumulative incidence estimates for VTE, which takes into account the competing risk of death (an event that precludes subsequent VTE occurrence) ${ }^{25}$

We then computed the rate of VTE within the categories described above for the two cohorts and created Cox proportional hazard regression models to compute the HRs as a measure of the VTE rate ratio adjusted for age (continuous) and year of BC diagnosis (1995-1999 vs 2005-2010, 2000-2004 vs 2005-2010) to compute rate ratios for VTE within the strata of comorbidity. As comorbid conditions were matched factors, the matching had to be dissolved in all adjusted analyses and for analyses of the 2-5 year survival cohort. To account for changes in the age distribution at 1 year of follow-up, VTE rates for the $2-5$ year survivor cohort were standardised to the age distribution of patients with $\mathrm{BC}$ as of their index dates. The proportionality assumption in 
Table 1 Characteristics of the breast cancer and the matched comparison cohorts, 1994-2010

\begin{tabular}{|c|c|c|c|c|}
\hline & \multicolumn{2}{|c|}{ Breast cancer cohort } & \multicolumn{2}{|c|}{ Comparison cohort } \\
\hline & Women, N & $(\%)$ & Women, N & (\%) \\
\hline \multicolumn{5}{|l|}{ Number of patients } \\
\hline $0-1$ year of follow-up & 62376 & & 304803 & \\
\hline $2-5$ years of follow-up & 57857 & & 296326 & \\
\hline \multicolumn{5}{|l|}{ Age group in years } \\
\hline $0-59$ & 27013 & $(43)$ & 134598 & $(44)$ \\
\hline $60-69$ & 17065 & $(27)$ & 81640 & (27) \\
\hline $70-79$ & 10846 & $(17)$ & 53000 & $(17)$ \\
\hline$\geq 80$ & 7452 & $(12)$ & 35565 & (12) \\
\hline \multicolumn{5}{|l|}{ Year of cancer diagnosis/index date* } \\
\hline 1995-1999 & 16949 & $(27)$ & 83263 & $(27)$ \\
\hline 2000-2004 & 18894 & $(30)$ & 92488 & (30) \\
\hline $2005-2010$ & 26533 & (43) & 129052 & (42) \\
\hline \multicolumn{5}{|l|}{ Cancer stage } \\
\hline Local & 28936 & $(46)$ & $\mathrm{N} / \mathrm{A}$ & \\
\hline Regional & 24210 & (39) & $\mathrm{N} / \mathrm{A}$ & \\
\hline Distant & 3302 & (5.3) & $\mathrm{N} / \mathrm{A}$ & \\
\hline Unknown & 5928 & $(9.5)$ & $\mathrm{N} / \mathrm{A}$ & \\
\hline \multicolumn{5}{|l|}{ Charlson Comorbidity Index score } \\
\hline 0 & 46856 & $(75)$ & 231713 & $(76)$ \\
\hline 1 & 8037 & (13) & 38854 & (13) \\
\hline $2-3$ & 6437 & (10) & 30419 & (10) \\
\hline$\geq 4$ & 1047 & $(1.7)$ & 3817 & (1.3) \\
\hline \multicolumn{5}{|c|}{ Individual comorbidities in the Charlson Comorbidity Index } \\
\hline Myocardial infarction & 1086 & $(1.7)$ & 4909 & $(1.6)$ \\
\hline Congestive heart failure & 1258 & $(2.0)$ & 5333 & $(1.7)$ \\
\hline Peripheral vascular disease & 1267 & $(2.0)$ & 5598 & (1.8) \\
\hline Cerebrovascular disease & 2919 & $(4.7)$ & 13530 & $(4.4)$ \\
\hline Dementia & 426 & $(0.7)$ & 1888 & $(0.6)$ \\
\hline Chronic pulmonary disease & 3118 & $(5.0)$ & 14446 & $(4.7)$ \\
\hline Connective tissue disease & 1471 & $(2.4)$ & 6766 & (2.2) \\
\hline Ulcer disease & 1623 & $(2.6)$ & 7509 & (2.5) \\
\hline Mild liver disease & 402 & $(0.6)$ & 1764 & $(0.6)$ \\
\hline Diabetes I and II & 1751 & $(2.8)$ & 7837 & (2.6) \\
\hline Hemiplegia & 87 & $(0.1)$ & 365 & $(0.1)$ \\
\hline Moderate to severe renal disease & 445 & $(0.7)$ & 1892 & $(0.6)$ \\
\hline Diabetes with end-organ damage & 653 & $(1.0)$ & 2832 & (0.9) \\
\hline Any tumour $†$ & 3221 & $(5.2)$ & 15196 & (5.0) \\
\hline Leukaemia & 66 & $(0.1)$ & 273 & $(0.1)$ \\
\hline Lymphoma & 189 & $(0.3)$ & 859 & (0.3) \\
\hline Moderate to severe liver disease & 77 & $(0.1)$ & 311 & $(0.1)$ \\
\hline Metastatic solid tumour & 296 & $(0.5)$ & 1320 & $(0.4)$ \\
\hline AIDS & 6 & (0) & 30 & (0) \\
\hline \multicolumn{5}{|l|}{ Other comorbidities } \\
\hline Atrial fibrillation & 567 & $(0.9)$ & 2453 & $(0.8)$ \\
\hline Obesity & 1330 & $(2.1)$ & 5984 & (2.0) \\
\hline \multicolumn{5}{|l|}{ Cases of VTE $\ddagger$} \\
\hline \multicolumn{5}{|l|}{$0-1$ year of follow-up } \\
\hline DVT & 195 & (39) & 309 & $(46)$ \\
\hline $\mathrm{PE}$ & 178 & (35) & 235 & (35) \\
\hline Other VTEs & 129 & $(26)$ & 124 & (19) \\
\hline \multicolumn{5}{|l|}{$2-5$ years of follow-up } \\
\hline DVT & 333 & $(26)$ & 1025 & (34) \\
\hline PE & 289 & $(22)$ & 827 & (28) \\
\hline Other VTEs & 167 & (13) & 456 & (15) \\
\hline
\end{tabular}




\begin{tabular}{|c|c|c|c|c|c|c|}
\hline \multicolumn{7}{|c|}{ 0-1 year follow-up } \\
\hline $\begin{array}{l}\mathrm{CCl} \\
\text { score }\end{array}$ & Cohort & $\begin{array}{l}\text { Number } \\
\text { of VTEs }\end{array}$ & Person-years & $\begin{array}{l}\text { Standard rate } \\
(95 \% \mathrm{CI})\end{array}$ & IC (95\% Cl) & $\begin{array}{l}\text { VTE rate ratio } \\
(95 \% \mathrm{Cl})\end{array}$ \\
\hline 0 & Breast & 324 & 45342 & 7.1 (6.4 to 7.9$)$ & Ref & 4.8 (4.1 to 5.6$)$ \\
\hline 0 & Comparison & 346 & 229978 & 1.5 (1.4 to 1.7$)$ & & \\
\hline 1 & Breast & 93 & 7543 & $12(10$ to 15$)$ & $3.2(0.5$ to 5.9$)$ & 3.5 (2.7 to 4.6$)$ \\
\hline 1 & Comparison & 134 & 37966 & 3.5 (3.0 to 4.2$)$ & & \\
\hline $2-3$ & Breast & 70 & 5936 & 12 (9.2 to 15$)$ & $1.2(-1.8$ to 4.2$)$ & $2.4(1.8$ to 3.1$)$ \\
\hline $2-3$ & Comparison & 146 & 29201 & $5.0(4.2$ to 5.8$)$ & & \\
\hline$\geq 4$ & Breast & 15 & 910 & 17 (9.2 to 26$)$ & $-1.3(-11$ to 7.9$)$ & $1.3(0.7$ to 2.4$)$ \\
\hline$\geq 4$ & Comparison & 42 & 3455 & 12 (8.8 to 16$)$ & & \\
\hline \multicolumn{7}{|c|}{$2-5$ year follow-up } \\
\hline 0 & Breast & 533 & 135618 & 4.3 (3.9 to 4.6$)$ & Ref & 2.2 (2.0 to 2.4 ) \\
\hline 0 & Comparison & 1384 & 747209 & 2.1 (2.0 to 2.2 ) & & \\
\hline 1 & Breast & 136 & 19861 & 6.4 (5.3 to 7.6$)$ & $0.9(-0.4$ to 2.1$)$ & 1.7 (1.4 to 2.1$)$ \\
\hline 1 & Comparison & 436 & 109138 & 3.4 (3.0 to 3.7$)$ & & \\
\hline $2-3$ & Breast & 100 & 14766 & 6.1 (4.7 to 7.5$)$ & $-0.5(-2.1$ to 1.0$)$ & $1.2(1.0$ to 1.6$)$ \\
\hline $2-3$ & Comparison & 433 & 79310 & 4.5 (4.0 to 5.0$)$ & & \\
\hline$\geq 4$ & Breast & 20 & 1834 & 10 (3.9 to 17$)$ & $2.3(-4.3$ to 8.9$)$ & 1.5 (0.9 to 2.5$)$ \\
\hline$\geq 4$ & Comparison & 55 & 7825 & 5.8 (4.0 to 7.5$)$ & & \\
\hline
\end{tabular}

Cox models was examined with $\log$ minus log plots, and both this and the linearity assumption of the effect of age were found to be acceptable. The interaction between BC and comorbidity on the rate of VTE was examined by calculating the IC, which measures the excess or deficit rate of VTE above or below that expected given the baseline VTE rate, the effect of BC on the VTE rate, and the effect of comorbidity on the VTE rate, based on the additivity of effects. It is calculated as the difference between the rate differences (VTE rate in the BC cohort minus the VTE rate in the comparison cohort) in the strata with and without comorbidity. ${ }^{16}$ The IC is a measure of the synergistic or antagonistic interaction between two factors that cannot be explained by their individual effects.

Analyses were conducted using SAS V.9.2 (SAS Institute Inc, Cary, North Carolina, USA).

The study was approved by the Danish Data Protection Agency (2011-41-6174).

\section{RESULTS}

Descriptive statistics of the cohorts are shown in table 1 . The study included 62376 patients with BC and 304803 women from the general population matched to the patients with BC diagnosed between 1995 and 2010. The median age in the BC cohort was 62.3 years (IQR 52.8, 72.3), and 62 (IQR 52.6, 72.9) in the comparison cohort. In the $\mathrm{BC}$ and comparison cohorts, $75 \%$ and $76 \%$ of all women had a CCI score of 0 at the index date. During the first year of follow-up, there were 502 $(0.8 \%)$ and $668(0.2 \%)$ cases of VTE in the BC and the matched comparison cohort, respectively, of which $39 \%$ vs $46 \%$ were DVT, $35 \%$ were PE in both cohorts, and $26 \%$ vs $19 \%$ were other VTEs, respectively. By 5 years of follow-up, an additional 789 (1.4\%) cases of VTE were diagnosed in the BC cohort and $2308(0.8 \%)$ in the comparison cohort.

Table 2 presents the VTE rates, ICs and adjusted VTE rate ratios for $0-1$ and 2-5 years of follow-up in the $\mathrm{BC}$ and comparison cohorts. After taking into account death as a competing risk, the $\mathrm{BC}$ cohort was at higher risk for all types of VTE within 1 year of follow-up $(0.80 \%, 95 \%$ CI 0.74 to 0.88 vs $0.22 \%, 95 \%$ CI 0.20 to 0.24$)$ and at 5 years of follow-up $(1.6 \%, 95 \%$ CI 1.50 to 1.73 vs $0.93 \%$, $95 \%$ CI 0.90 to 0.97$)$. At 1 year of follow-up, the VTE rate was 8.4 (95\% CI 7.7 to 9.2$)$ per 1000 person-years (PY) in the BC cohort and 2.2 (95\% CI 2.1 to 2.4) per $1000 \mathrm{PY}$ in the comparison cohort (data not shown). In all strata of CCI scores, the BC cohort had higher rates of VTE compared to the comparison cohort, but the corresponding HRs decreased with increasing CCI score. The HR for VTE was 4.8 (95\% CI 4.1 to 5.6) for a CCI score of 0 , and 1.3 (95\% CI 0.7 to 2.4 ) for a CCI score of $\geq 4$. During $2-$ 5 years of follow-up, the corresponding HRs were 2.2 (95\% CI 2.0 to 2.4) for a CCI score of 0 and 1.5 (95\% CI 0.9 to 2.5 ) for a CCI score of $\geq 4$.

The IC analysis revealed a small amount of interaction between BC and the CCI score, which weakened with increasing CCI score, suggesting that the combined effect of BC and comorbidity mainly impacts the VTE rates in the presence of low comorbidity levels. Interaction accounted for 3.2 (95\% CI 0.5 to 5.9$)$ cases of VTE per 1000 PY for a CCI score of $1,1.2(95 \%$ CI -1.8 to 4.2) cases of VTE for a CCI score of $2-3$, and -1.3 (95\% CI -11 to 7.9 ) cases of VTE for a CCI score of $\geq 4$ / 
1000 PY, representing $27 \%, 10 \%$ and $-7.6 \%$ of total VTE rates, respectively. During 2-5 years of follow-up, weak interaction was only observed for the CCI score of $\geq 4$ (IC, 2.3, 95\% CI -4.3 to $8.9 / 1000 \mathrm{PY}$ ), corresponding to $23 \%$ of the total VTE rate.

\section{DISCUSSION}

In this nationwide study, the BC cohort had elevated rates of VTE compared to women from the comparison cohort in all categories of comorbidity. However, comparing the $\mathrm{BC}$ cohort to the comparison cohort within levels of the CCI score, the VTE rate differences remained nearly constant as the comorbidity level increased, whereas the rate ratios declined with increasing CCI score. We found that there was only a small amount of interaction between BC and the CCI score on the VTE rate, which primarily was observed during the first year after BC diagnosis for patients with a CCI score of 1 . This pattern of effects and interactions suggests that comorbidity and $\mathrm{BC}$ or its treatment affect the rate of VTE for patients with BC with a CCI score of 1 and in the first year of follow-up. Previous studies have found that BC does not confer a large increased risk of VTE compared to many other cancer types, ${ }^{3}$ which may provide one explanation for the relatively small amount of interaction in patients with $\mathrm{BC}$ compared to women from the general population.

Interaction contrasts were negative in some analyses, although often imprecisely measured. Negative interaction contrasts suggest that the joint effect of BC and comorbidity is less than expected from their individual effects. In women with multiple comorbidities, and at longer times of follow-up, the independent effects of comorbidity and $\mathrm{BC}$ therefore dominate the overall risk of VTE, possibly due to the higher baseline risk of VTE contributed by each of these factors.

In our study, patients with BC had higher VTE rates than the comparison cohort women in all strata of comorbidity, particularly in the first year of follow-up. Such an effect is probably due to a prothrombotic state associated with the cancer and cancer-directed treatments such as surgery, chemotherapy and antihormonal therapies. ${ }^{142627}$ Other medications used to treat cancer symptoms and comorbid conditions, such as NSAIDs and glucocorticoids, could elevate VTE risk. ${ }^{28}{ }^{29}$ With increasing CCI score, the rates of VTE in the two cohorts approached each other. This finding may be explained by a potentially greater effect of the cumulative comorbidity burden on the VTE risk, while the effect of BC remains similar within each strata of comorbidity.

Therefore, the presence of comorbidity may be a factor worth considering in future prediction models.

This study was based on a nationwide cohort of patients with $\mathrm{BC}$, and we achieved almost complete follow-up through the CRS, limiting selection bias.

Despite these strengths, there are several study limitations to consider. Data on BC obtained from the DCR are virtually complete. ${ }^{30}$ The positive predictive values for the CCI diseases recorded in the DNRP are above $80 \%$ compared to the medical record review. ${ }^{31}$ However, outpatient data were not registered before 1995, and the impact of any resulting misclassification of comorbidities on estimates of the interaction contrast is unclear. ${ }^{32}$ The definition of VTE included both inpatient and outpatient discharge VTE diagnoses, but the accuracy of these diagnoses varies for type of diagnosis and hospital department, with the highest positive predictive value of $75 \%$ for inpatient diagnoses. ${ }^{24}$ To reduce the number of invalid VTE diagnoses, we only included inpatient and outpatient VTE diagnoses, thereby disregarding VTE only diagnosed at emergency departments, which have poor predictive value. ${ }^{24}$ Any bias resulting from the potential rate of misclassification could be affected by a diagnosis of $\mathrm{BC}$ and lead to surveillance bias, because patients receive thorough medical care, particularly in the initial years following diagnosis. ${ }^{33}$ With increasing CCI score, the VTE rates among patients with BC approach the rates of comparison women, suggesting that the amount of medical surveillance is more similar between the cohorts with increasing morbidity. In addition, intravenous catheters used in connection with cancer surgery or chemotherapy are linked to VTE. ${ }^{34}$ Such associations could affect the accuracy of DVT diagnoses. Furthermore, we lacked information on several important factors, for example, cancer treatment, abnormal laboratory findings, other medications and intravenous catheters, which could independently affect VTE risk.

In summary, we found only little interaction between BC and the CCI score on the rate of VTE. While there was little interaction, it does appear that patients and physicians should consider comorbidities when contemplating prophylactic anticoagulation for patients with BC.

\section{Author affiliations}

${ }^{1}$ Department of Clinical Epidemiology, Aarhus University Hospital, Aarhus, Denmark

${ }^{2}$ Breast Clinic, Aalborg University Hospital, Aalborg, Denmark ${ }^{3}$ Department of Oncology, Uppsala University Hospital, Uppsala, Sweden ${ }^{4}$ Institute of Pathology, Aalborg University Hospital, Aalborg, Denmark ${ }^{5}$ Department of Epidemiology, Rollins School of Public Health, Emory University, Atlanta, Georgia, USA

Contributors AGO, HTS and TLL conceived and designed the study. AGO, EHP, HTS and TLL acquired, analysed and interpreted the data. AGO wrote the first draft and EHP, JPG, PWN, HTS, MV and TLL reviewed, revised and approved the manuscript.

Funding The study was supported by the Danish Cancer Society (grant no. R73-A4284-13-S17); the Danish Agency for Science, Technology and Innovation (record number: 10-084581); Karen Elise Jensen Foundation; Aarhus University Research Foundation; the Clinical Epidemiology Research Foundation, Aarhus University; Aalborg Hospital, Region North Denmark. The funding sources had no role in the design, analysis and interpretation of the study.

Competing interests The Department of Clinical Epidemiology, Aarhus University Hospital, receives funding for other studies from companies in the form of research grants to (and administered by) Aarhus University. None of these studies have any relation to the present study. 
Ethics approval The study was approved by the Danish Data Protection Agency (2011-41-6174).

Provenance and peer review Not commissioned; externally peer reviewed.

Data sharing statement No additional data are available.

Open Access This is an Open Access article distributed in accordance with the Creative Commons Attribution Non Commercial (CC BY-NC 3.0) license which permits others to distribute, remix, adapt, build upon this work noncommercially, and license their derivative works on different terms, provided the original work is properly cited and the use is non-commercial. See: http:// creativecommons.org/licenses/by-nc/3.0/

\section{REFERENCES}

1. Lyman $\mathrm{GH}$. Venous thromboembolism in the patient with cancer focus on burden of disease and benefits of thromboprophylaxis. Cancer 2011;117:1334-49.

2. Sorensen HT, Mellemkjaer L, Olsen JH, et al. Prognosis of cancers associated with venous thromboembolism. $N$ Engl J Med 2000;343:1846-50.

3. Cronin-Fenton DP, Sondergaard F, Pedersen LA, et al. Hospitalisation for venous thromboembolism in cancer patients and the general population: a population-based cohort study in Denmark 1997-2006. Br J Cancer 2010;103:947-53.

4. Heit JA, Silverstein MD, Mohr DN, et al. Risk factors for deep vein thrombosis and pulmonary embolism: a population-based case-control study. Arch Intern Med 2000;160:809-15.

5. Blom JW, Doggen CJ, Osanto $\mathrm{S}$, et al. Malignancies, prothrombotic mutations, and the risk of venous thrombosis. JAMA 2005;293:715-22.

6. Chew HK, Wun T, Harvey DJ, et al. Incidence of venous thromboembolism and the impact on survival in breast cancer patients. J Clin Oncol 2007;25:70-6.

7. Khorana AA, Francis CW, Culakova E, et al. Frequency, risk factors and trends for venous thromboembolism among hospitalized cancer patients. Cancer 2007;110:2339-46.

8. Verso M, Agnelli G. Venous thromboembolism associated with long-term use of central venous catheters in cancer patients. J Clin Oncol 2003;21:3665-75.

9. Ferlay J, Shin HR, Bray F, et al. Estimates of worldwide burden of cancer in 2008: GLOBOCAN 2008. Int J Cancer 2010;127:2893-917.

10. Cronin-Fenton DP, Norgaard M, Jacobsen J, et al. Comorbidity and survival of Danish breast cancer patients from 1995 to $2005 . \mathrm{Br} \mathrm{J}$ Cancer 2007;96:1462-8.

11. Glynn RJ, Rosner B. Comparison of risk factors for the competing risks of coronary heart disease, stroke, and venous thromboembolism. Am J Epidemiol 2005;162:975-82.

12. Prandoni $\mathrm{P}$, Bilora $\mathrm{F}$, Marchiori $\mathrm{A}$, et al. An association between atherosclerosis and venous thrombosis. $N$ Engl J Med 2003;348:1435-41.

13. Breart G, Cooper C, Meyer O, et al. Osteoporosis and venous thromboembolism: a retrospective cohort study in the UK General Practice Research Database. Osteoporos Int 2010;21:1181-7.

14. Anderson FA Jr, Spencer FA. Risk factors for venous thromboembolism. Circulation 2003;107(23 Suppl 1):I9-16.
15. Charlson ME, Pompei $\mathrm{P}$, Ales $\mathrm{KL}$, et al. A new method of classifying prognostic comorbidity in longitudinal studies: development and validation. J Chronic Dis 1987;40:373-83.

16. Rothman KJ, Greenland S, Lash TL. Concepts of interaction Modern epidemiology. 3rd edn. Philadelphia: Lippincott Williams \& Wilkins, 2008:71-86.

17. Tsai AW, Cushman M, Rosamond WD, et al. Cardiovascular risk factors and venous thromboembolism incidence: the longitudinal investigation of thromboembolism etiology. Arch Intern Med 2002;162:1182-9.

18. Lip GY, Tse HF. Management of atrial fibrillation. Lancet 2007;370:604-18.

19. Frank L. Epidemiology. When an entire country is a cohort. Science 2000;287:2398-9.

20. Pedersen $\mathrm{CB}$, Gotzsche H, Moller JO, et al. The Danish Civil Registration System. A cohort of eight million persons. Dan Med Bull 2006;53:441-9.

21. Storm HH, Michelsen EV, Clemmensen IH, et al. The Danish Cancer Registry-history, content, quality and use. Dan Med Bull 1997;44:535-9.

22. Gjerstorff ML. The Danish Cancer Registry. Scand J Public Health 2011;39(7 Suppl):42-5

23. Andersen TF, Madsen M, Jorgensen J, et al. The Danish National Hospital Register. A valuable source of data for modern health sciences. Dan Med Bull 1999;46:263-8.

24. Severinsen MT, Kristensen SR, Overvad K, et al. Venous thromboembolism discharge diagnoses in the Danish National Patient Registry should be used with caution. J Clin Epidemiol 2010;63:223-8.

25. Andersen PK, Geskus RB, de Witte T, et al. Competing risks in epidemiology: possibilities and pitfalls. Int J Epidemiol 2012;41:861-70.

26. Mandala M, Barni S, Prins M, et al. Acquired and inherited risk factors for developing venous thromboembolism in cancer patients receiving adjuvant chemotherapy: a prospective trial. Ann Oncol 2010;21:871-6.

27. Degen JL, Palumbo JS. Hemostatic factors, innate immunity and malignancy. Thromb Res 2012;129(Suppl 1):S1-5.

28. Johannesdottir SA, Horvath-Puho E, Dekkers OM, et al. Use of glucocorticoids and risk of venous thromboembolism: a nationwide population-based case-control study. JAMA Intern Med 2013;173:743-52.

29. Schmidt M, Christiansen CF, Horvath-Puho E, et al. Non-steroidal anti-inflammatory drug use and risk of venous thromboembolism. $J$ Thromb Haemost 2011:9:1326-33.

30. Jensen AR, Overgaard J, Storm HH. Validity of breast cancer in the Danish Cancer Registry. A study based on clinical records from one county in Denmark. Eur J Cancer Prev 2002;11:359-64.

31. Thygesen SK, Christiansen CF, Christensen S, et al. The predictive value of ICD-10 diagnostic coding used to assess Charlson comorbidity index conditions in the population-based Danish National Registry of Patients. BMC Med Res Methodol 2011;11:83

32. Greenland $\mathrm{S}$. The effect of misclassification in the presence of covariates. Am J Epidemiol 1980;112:564-9.

33. Moller S, Jensen MB, Ejlertsen B, et al. The clinical database and the treatment guidelines of the Danish Breast Cancer Cooperative Group (DBCG); its 30-years experience and future promise. Acta Oncol 2008;47:506-24.

34. Caine GJ, Stonelake PS, Rea D, et al. Coagulopathic complications in breast cancer. Cancer 2003;98:1578-86. 